\title{
Near vision impairment among the elderly in residential care-the Hyderabad Ocular Morbidity in Elderly Study (HOMES)
}

\author{
Srinivas Marmamula $\mathbb{D}^{1,2,3,4} \cdot$ Navya Rekha Barrenkala $\mathbb{D}^{1} \cdot$ Rohit C. Khanna $^{1,4} \cdot$ Rajesh Challa $^{1} \cdot$ Madhuri Bhakki $^{1}$. \\ Thirupathi Reddy Kumbham ${ }^{1}$. Satya Brahmanandam Modepalli ${ }^{1} \cdot$ Ratnakar Yellapragada $^{1} \cdot$ David S. Friedman $^{5}$
}

Received: 14 April 2020 / Revised: 10 September 2020 / Accepted: 16 October 2020 / Published online: 6 November 2020

(c) The Author(s), under exclusive licence to The Royal College of Ophthalmologists 2020

\begin{abstract}
Background/objective To report on the prevalence and risk factors for near vision impairment (NVI) among the elderly in residential care in Telangana State in India.

Methods Individuals aged $\geq 60$ years were recruited from 41 'home for the aged' centres in Hyderabad, India. All participants had complete eye examinations including presenting and best-corrected visual acuity assessment for distance and near. NVI was defined as binocular presenting near vision worse than N8 (6/15) among those who had a normal presenting distance visual acuity of $6 / 18$ in the better eye.

Results Of the 826 participants, the mean age was 74.4 years (standard deviation-8.4 years), 525 (63.6\%) were women, $715(86.6 \%)$ had at least school education. The prevalence of NVI was $51.2 \%$ (95\% CI: 47.7-54.7) based on presenting vision. On applying multiple logistic regression analysis, the odds of NVI were higher in 80 years and older age (OR: 2.17; 95\% CI: 3.44-13.6). Those with school education (OR: 0.58: 95\% CI: 0.36-0.94) and higher education (OR: 0.38; 95\% CI: 0.21-0.69) had lower odds for NVI. Similarly, those with self-reported diabetes (OR: 0.69; 95\% CI: 0.49-0.97), those using spectacles (OR: 0.09; 95\% CI: 0.05-0.16), and those who had undergone cataract surgery (OR: 0.51; 95\% CI: 0.36-0.74) had lower odds for NVI.

Conclusions NVI was common among the elderly in residential care in homes for the aged in Hyderabad, India. As most of this NVI is correctable, a routine screening programme and dispensing of spectacles can be undertaken to address this vision loss.
\end{abstract}

\section{Introduction}

Globally, over 1.1 billion people have near vision impairment (NVI) [1], the vast majority of which is due to presbyopia [2].

Srinivas Marmamula

sri.marmamula@lvpei.org

1 Allen Foster Community Eye Health Research Centre, Gullapalli Pratibha Rao International Centre for Advancement of Rural Eye care, L V Prasad Eye Institute, Hyderabad, India

2 Brien Holden Institute of Optometry and Vision Science, L V Prasad Eye Institute, Hyderabad, India

3 Wellcome Trust/Department of Biotechnology India Alliance, L V Prasad Eye Institute, Hyderabad, India

4 School of Optometry and Vision Science, University of New South Wales, Sydney, NSW, Australia

5 Harvard Medical School Department of Ophthalmology, Massachusetts Eye and Ear, Harvard Medical School, Boston, MA, USA
Over 826 million have NVI due to inadequate or lack of correction [1]. The prevalence of presbyopia varies significantly across different regions and also with the definitions used [3-13]. Cataract surgery with intraocular lens implantation also can result in NVI with a need for spectacles for near vision. NVI is easily corrected with spectacles at the community level without the need for complex eye care infrastructure and resources. The global productivity loss due to uncorrected presbyopia in the year 2011 was reported as the US\$11 billion [14]. Studies have also shown an increase in productivity with appropriate correction of presbyopia [15].

India is aging and presbyopia will become an increasingly large problem. Homes for the aged are emerging as a more socially acceptable concept in India and there is a rapid increase in the number of such homes. The data on the health status of the elderly are limited in general, particularly for eye health. With this background, the longitudinal Hyderabad Ocular Morbidity in Elderly Study (HOMES) was designed to provide vital data on vision impairment and eye health status in the elderly in residential care in India 
[16]. The information from this study is expected to provide the basis for developing eye care programmes for the elderly throughout India. We previously have reported on the burden of vision impairment for distance and uncorrected refractive error in this population $[17,18]$. The purpose of this paper is to report on the prevalence and risk factors of NVI among elderly individuals living in residential care in Hyderabad in South India.

\section{Materials and methods}

\section{Ethics approval}

The HOMES study protocol was approved by the Institutional Review Board of the Hyderabad Eye Research Foundation, L V Prasad Eye Institute, and adhered to the tenets of the Declaration of Helsinki. Each participant provided written informed consent indicating their willingness to participate in the study.

HOMES was conducted in 'homes for the aged' in Hyderabad and adjoining regions of the Greater Hyderabad Municipal Corporation in Telangana state. In total, 41 homes were included in the study. All the residents aged 60 years and older and residing in the homes for at least 1 month and willing to participate were included in the study [18].

\section{Study participants}

In HOMES, 1182 out of 1513 (78.1\%) eligible participants were examined. Those examined and not examined were similar in terms of gender $(p=0.31)$, however, the mean age of those examined was slightly higher (75.0 versus 74.2 years; $p=0.05)$. Among those examined, $356(30.1 \%)$ had vision impairment (moderate or worse) for distance (presenting visual acuity (VA) worse than $6 / 18$ in the better eye) and were excluded from the analysis [18]. The data of the remaining 826 participants were analysed. This number of participants was sufficient to assess the prevalence of NVI with good precision.

\section{Eye examination}

A makeshift clinic was set up in each of the homes and eye examinations were carried out. Detailed personal and demographic information was collected before the eye examination including age, gender, education, and marital status. Self-report of diabetes and hypertension were also collected. The HOMES examination protocol has been described in detail in our previous publications [16-18]. In short, the eye examination included visual acuity (VA) assessment for distance and near, refraction, slit-lamp biomicroscopy, intraocular pressure measurement, undilated fundus examination, and retinal imaging. Presenting binocular near vision was recorded in all individuals using a Logarithm of the Minimum Angle of Resolution chart at a fixed distance of $40 \mathrm{~cm}$ under ambient lighting conditions. A light meter (Lutron LX-102 Light Meter, Taiwan) was used to measure illumination. A minimum of 180 lux was required for near vision assessment. Good lighting was ensured by arranging the seating position of the subject closer to the windows and the door. At the same time precautions were taken to avoid glare. Additionally, wherever possible the testing was carried out in open areas such as corridors, dining halls, and prayer/meeting halls in the homes. Both English letter optotypes and tumbling E optotype VA charts were used. A letter by letter scoring method was used. The last optotype that was identified correctly was considered as an endpoint and recorded in log MAR. Any participant who failed to identify even a single optotype beyond the 0.4 line ( $\mathrm{N} 8$ equivalent) on the chart binocularly was considered to have NVI. The VA was tested with the participant's spectacles if used for seeing objects at near. All subjects underwent objective refraction (manual and autorefraction) as well as subjective refraction; best-corrected VA was recorded for both distance and near vision. NVI was defined as presenting near vision worse than $\mathrm{N} 8(6 / 15)$ at $40 \mathrm{~cm} .[19,20]$.

\section{Data management}

Data were entered into a database created in Microsoft Access and the data analysis was carried out using Stata Statistical Software for Windows, version 14 (StataCorp, College Station, TX) [15]. The prevalence of NVI was calculated and reported with $95 \%$ confidence intervals. Univariable and multivariable logistic regression analyses were performed to identify the factors associated with NVI. Hosmer-Lemeshow goodness of fit test was used to assess the model. Variance inflation factors were used to test for collinearity between the covariates after fitting a bogus multiple regression model. The odds ratio with $95 \%$ confidence intervals was calculated. A two-tailed $p$ value $<0.05$ was considered statistically significant.

\section{Results}

\section{Characteristics of the study participants}

Of the 826 participants included in the analysis, the mean age was 74.4 years (standard deviation -8.4 years; range: 60-97 years), 525 (63.6\%) were women, $715(86.6 \%)$ had at least school education, $112(13.6 \%)$ were staying in 'free homes', 349 (42.3\%) were from 'aided/subsidised' homes and 365 (44.2\%) were from paid/private homes. In terms of 
systemic conditions, $500(60.5 \%)$ reported having hypertension and $261(31.6 \%)$ had diabetes. At the time of examination, $653(79.1 \%)$ were using spectacles for near and $544(65.9 \%)$ had undergone cataract surgery in at least one eye (Table 1). Spectacle use for near was associated with older age $(p=0.012)$ and a higher level of education $(p<0.01)$. In all, $438(53 \%)$ participants had an eye examination within the last 2 years. Reading books/newspapers was reported as an important leisure activity by 417 (50.5\%) of the participants, followed by watching television by $336(40.7 \%)$ and helping in routine household activities by $118(14.3 \%)$ participants.

\section{Prevalence and risk factors of NVI}

The prevalence of NVI was $51.2 \%$ (95\% CI: 47.7-54.7; $n=423$ ) based on presenting vision. In univariable analysis, the prevalence of NVI was lower among those with higher levels of education ( 66.7 versus $40.9 \% ; p<0.01)$ and among those who self-reported diabetes (44.0 versus $54.5 \% ; p<0.01)$. The prevalence was also lower among current spectacle users for near compared to those without spectacles $(41.7$ versus $87.3 \%, p<0.01)$ and among those operated for cataract in at least one eye (47.4 versus $58.5 \%$, $p<0.01$ ) NVI (Table 1).

Among the participants with NVI, 263 (62.2\%) participants improved by one line or more with the best correction. Of these, $112(42.6 \%)$ improved by one line, 95 (36.1\%) improved by two lines, and $56(21.3 \%)$ improved by three or more lines with correction.

Among the current spectacle wearers with NVI $(n=$ 272), $30.5 \%(n=83)$ of them improved by one line, $19.5 \%$ $(n=53)$ improved by 2 lines, $7.0 \%(n=19)$ improved by $\geq 3$ lines with new correction. Similarly, among those who were not using spectacles for near, $19.2 \%$ improved by one line, $27.8 \%$ improved by two lines and $24.5 \%$ improved by $\geq 3$ lines. Those without spectacles had more lines for improvement $(p<0.01)$.

Those who did not have improved near vision with correction (96/423 participants; 37.8\%) had mild levels of visual impairment (worse than 6/12 and equal to 6/18) for distance and therefore not excluded from the study owing to vision impairment definition used $(<6 / 18)$. Among these, a large proportion had early cataract $(n=54)$ followed by posterior segment pathology (unhealthy appearing macula $(n=13)$, diabetic retinopathy $(n=3)$ and optic nerve changes $(n=4)$.

On applying multiple logistic regression analysis, the odds of NVI were higher in 80 years and older age groups as compared to those in 60-69 years age group (OR: 2.17; 95\% CI: 3.44-13.6). Compared to those without any education, those with school education (OR: 0.58: $95 \% \mathrm{CI}$ : 0.36-0.94) and higher education (OR: $0.38 ; 95 \% \mathrm{CI}$ :
Table 1 Characteristics of the study participants and the prevalence of NVI (univariable analysis).

\begin{tabular}{|c|c|c|c|}
\hline & $\begin{array}{l}\text { Total in the } \\
\text { sample }(n=826)\end{array}$ & $\begin{array}{l}\text { Near vision } \\
\text { impairment } n(\%)^{\mathrm{a}}\end{array}$ & $p$ \\
\hline Age group (years) & & & 0.367 \\
\hline $60-69$ & 244 & $126(51.6)$ & \\
\hline $70-79$ & 330 & $160(48.5)$ & \\
\hline 80 and above & 252 & $137(54.4)$ & \\
\hline Gender & & & 0.87 \\
\hline Male & 301 & $153(50.8)$ & \\
\hline Female & 525 & $270(51.4)$ & \\
\hline Education level & & & $<0.01$ \\
\hline No schooling & 111 & 74 (66.7) & \\
\hline School education & 529 & $273(51.6)$ & \\
\hline Higher education & 186 & $76(40.9)$ & \\
\hline Years of residence & & & 0.38 \\
\hline$<5$ years & 542 & $286(52.8)$ & \\
\hline 5-9 years & 148 & $74(50.0)$ & \\
\hline$\geq 10$ & 136 & $63(46.3)$ & \\
\hline Hypertension & & & 0.315 \\
\hline Yes & 500 & $249(49.8)$ & \\
\hline No & 326 & $174(53.4)$ & \\
\hline Diabetes & & & 0.005 \\
\hline Yes & 261 & $115(44.1)$ & \\
\hline No & 565 & $308(54.5)$ & \\
\hline Mobility score & & & $<0.01$ \\
\hline Immobile/Bedridden & 53 & $35(66)$ & \\
\hline Mobile with support & 243 & $139(57.2)$ & \\
\hline Independent & 530 & $249(47.0)$ & \\
\hline Type of home & & & 0.1 \\
\hline Private home & 365 & $171(46.8)$ & \\
\hline Aided/partially paid & 349 & $187(53.6)$ & \\
\hline Free & 112 & $65(58.0)$ & \\
\hline Smoking status & & & 0.89 \\
\hline Never & 683 & $349(51.1)$ & \\
\hline Current/past & 143 & $74(51.7)$ & \\
\hline Alcohol consumption & & & 0.14 \\
\hline Never & 689 & $345(50.1)$ & \\
\hline Current/past & 137 & $78(56.9)$ & \\
\hline $\begin{array}{l}\text { Present spectacles } \\
\text { use for near }\end{array}$ & & & $<0.001$ \\
\hline Yes & 653 & $272(41.7)$ & \\
\hline No & 173 & $151(87.3)$ & \\
\hline Last eye check-up ${ }^{b}$ & & & $<0.01$ \\
\hline$<2$ years & 438 & $191(43.6)$ & \\
\hline$\geq 2$ years & 364 & $209(57.4)$ & \\
\hline $\begin{array}{l}\text { Cataract surgery in } \\
\text { either eye }\end{array}$ & & & $<0.01$ \\
\hline Yes & 544 & $258(47.4)$ & \\
\hline No & 282 & $165(58.5)$ & \\
\hline Total & 826 & $423(51.2)$ & \\
\hline
\end{tabular}

${ }^{\mathrm{a}}$ Row percentage presented.

${ }^{\mathrm{b}}$ Data not available on 24 participants.

0.21-0.69) had lower odds for NVI. Similarly, those with self-reported diabetes (OR: 0.69; 95\% CI: 0.49-0.97), those using spectacles (OR: 0.09; 95\% CI: 0.05-0.16), and those who had undergone cataract surgery (OR: $0.51 ; 95 \% \mathrm{CI}$ : 
0.36-0.74) had lower odds for NVI. Gender, type of home, years of residence at home, and self-report of hypertension were not associated with NVI (Table 2).

\section{Discussion}

More than half of the residents in homes for the aged in Hyderabad had NVI, of which over $60 \%$ could be easily be addressed by dispensing a pair of new spectacles. Half of the participants reported that they had not had an eye examination within the last 2 years. This highlights a large unmet need for correction of NVI among the elderly in residential care. Older individuals spend much of their time engaged in near tasks, and reading was rated the most important leisure activity among the elderly in our study. A lack of clear near vision can significantly impact their quality of life $[12,20]$.

Strikingly, nearly half of those studied who had spectacles for use at near still had NVI. As we reported previously, these residents of homes for the elderly need more frequent eye examinations to update their spectacles [17]. Furthermore, nearly half the participants had prior cataract surgery and a substantial proportion of these individuals had presenting NVI. This same group has a large burden of uncorrected and inadequately corrected refractive errors for distance [18]. Clearly, for cataract surgical services to be truly successful programmes, there is a need to place more emphasis on longterm outcomes including the need for spectacles and monitoring for posterior capsular opacification [18].

Several population-based studies in India and elsewhere have reported a high burden of NVI [1, 2, 4, 5, 7, 10, 21-24] with prevalence ranging from as low as $45 \%$ in Prakasam district in India to as high as $89 \%$ in East Africa $[1,2,4,5,7,10,21-24]$. Over one billion people suffer from NVI worldwide [2]. We reported a large unmet need for presbyopic correction among the elderly living in residential care in rural areas in our previous publication [25]. The prevalence of NVI is higher in our study compared to $<40 \%$ found in earlier studies from the same state is possibly due to the older age of the participants in our study compared to those aged 40 years and older in other studies [23, 26].

We found that the oldest residents in our study had the highest odds of NVI likely owing to limited uptake of services due to systemic comorbidities. Also, $46 \%$ of the participants had issues with mobility hence were unable to access eye care services as they are dependent on either home authorities or family members to seek eye care. As expected, those with a higher level of education had lower odds for NVI. These individuals likely are more sensitive to decreased near vision and seek care to correct their presbyopia. Higher education is also an indicator of a better economic status and hence these individuals likely had
Table 2 Multivariate analysis showing the association between NVI and socio-demographic variables and other risk factors.

\begin{tabular}{|c|c|c|}
\hline & $\begin{array}{l}\text { Odds ratio }(95 \% \\
\text { confidence intervals) }\end{array}$ & $p$ values \\
\hline \multicolumn{3}{|l|}{ Age group (years) } \\
\hline \multicolumn{3}{|l|}{$60-69$} \\
\hline $70-79$ & $1.30(0.87-1.95)$ & 0.19 \\
\hline 80 and above & $2.17(1.37-3.44)$ & $<0.01$ \\
\hline \multicolumn{3}{|l|}{ Gender } \\
\hline Male & Reference & \\
\hline Female & $1.00(0.65-1.55)$ & 1.00 \\
\hline \multicolumn{3}{|l|}{ Education } \\
\hline No education & Reference & \\
\hline School education & $0.58(0.36-0.94)$ & 0.03 \\
\hline Higher education & $0.38(0.21-0.69)$ & $<0.01$ \\
\hline \multicolumn{3}{|l|}{ Type of homes } \\
\hline Free home & Reference & \\
\hline Partially paid/aided & $1.02(0.63-1.66)$ & 0.93 \\
\hline $\begin{array}{l}\text { Completely paid/ } \\
\text { private homes }\end{array}$ & $0.76(0.46-1.28)$ & 0.3 \\
\hline \multicolumn{3}{|l|}{ Years of residence } \\
\hline$<5$ years & Reference & \\
\hline $5-9$ years & $0.99(0.65-1.50)$ & 0.96 \\
\hline$\geq 10$ years & $0.77(0.51-1.18)$ & 0.24 \\
\hline \multicolumn{3}{|l|}{ Smoking status } \\
\hline Present & Reference & \\
\hline Past/current & $1.04(0.62-1.77)$ & 0.87 \\
\hline \multicolumn{3}{|l|}{ Alcohol status } \\
\hline Present & Reference & \\
\hline Past/current & $1.26(0.77-2.07)$ & 0.36 \\
\hline \multicolumn{3}{|l|}{ Diabetes } \\
\hline No & Reference & \\
\hline Yes & $0.69(0.49-0.97)$ & 0.03 \\
\hline \multicolumn{3}{|l|}{ Hypertension } \\
\hline No & Reference & \\
\hline Yes & $0.96(0.70-1.33)$ & 0.83 \\
\hline \multicolumn{3}{|l|}{ Present spectacle use } \\
\hline No & Reference & \\
\hline Yes & $0.09(0.05-0.16)$ & $<0.01$ \\
\hline \multicolumn{3}{|l|}{ Cataract surgery } \\
\hline No & Reference & \\
\hline Yes & $0.51(0.36-0.74)$ & $<0.01$ \\
\hline
\end{tabular}

${ }^{a}$ Near vision impairment as the outcome and all the predictors entered at the same time.

${ }^{\mathrm{b}}$ Hosmer-Lemeshow test for goodness of fit for the regression model, $p=0.64$.

${ }^{\mathrm{c}}$ Mean variance inflation factor (VIF) for the multiple logistic regression model $=1.28$

more resources at their disposal to seek eye care. We found a higher prevalence of spectacle use for near among those with higher levels of education. That said, rates of NVI 
were similar in all types of homes with no difference in charitable homes versus paid ones. While counterintuitive, those with diabetes had lower rates of NVI. While one explanation for the lower rate of NVI among diabetics might have been more frequent eye examinations, as per the self-report, this was not the case. It is difficult to explain this finding.

Also, those with present spectacles and those who had cataract surgery had lower odds for NVI. Our region has unusually high rates of cataract surgery largely owing to the sustained outreach of several non-government eye hospitals focused on ensuring that all those who need it can access cataract surgery. The high prevalence of NVI suggests a lack of follow-up care after initial cataract surgery. We also found that years of residence was not associated with NVI. Most elderly $(65 \%)$ were in homes for $<5$ years.

We found that over a third of the participants could not improve in their presenting near vision with correction suggestive of underlying pathology (cataract and macular degeneration). We used presenting near vision worse than N8 as a criterion for defining NVI as this letter-size corresponds to the font size used in newspapers and other reading material. This is also recommended by other researchers [2]. We have used presenting VA as it represents the day-to-day 'real-life' vision of the participants. Our previous report on NVI also used a similar approach [27].

We have included only the participants who had presenting distance VA of $6 / 18$ or better in the better eye. This inclusion criterion certainly led to an underestimation of NVI in our study as those with distance VI were excluded. Those excluded included some with VI due to uncorrected refractive errors. Had we included these participants, more people might have benefited from refractive correction for NVI. Over $95 \%$ of those who had distance VI also had NVI. We included homes for the aged centres in the urban region and hence results from our study can be extrapolated to other urban areas in India. We had a good response rate and undertook a comprehensive eye health assessment. However, we have not recorded unaided near vision and hence unable to calculate the spectacles coverage for presbyopia.

The policy and programme implications of this study are significant. Over $60 \%$ of NVI can be corrected easily and inexpensively using spectacles and can be expected to benefit the elderly to regain good near vision. Homes for the aged are becoming more common in urban areas in India. As the eye care situation in urban areas across the country is similar, we believe that our results are generalizable to other urban regions in the country as a whole. Currently, eye care is not provided as a routine in homes for the aged in India.

There is thus a need for a systematic approach that includes regular eye examinations and provision of spectacles for distance and near vision. In our previous publications, we have proposed several approaches to address uncorrected refractive errors in the elderly in residential care and most of them will apply to address NVI as well [17]. A third of the elderly had not had an eye examination in the last 3 years which established the need for eye care providers to 'reach out' to the elderly in homes. Presbyopia correction is a basic minimum that can be provided at a low cost to the elderly to enhance their quality of life. Most leisure time activities that older people are engaged in require near vision. Correction of their presbyopia could improve their quality of life. In conclusion, our study provides valuable insights on NVI which could help in planning eye care services for the elderly in residential care to contribute towards healthy aging in India.

\section{Summary}

\section{What was known before}

- Near vision impairment is common in the elderly population. There is limited data on vision impairment among the elderly in residential care.

\section{What this study adds}

- Highlights the burden of near vision impairment among the elderly in residential care in India.

Acknowledgements The authors thank the individuals for their participation in the study. Mr. Shashank Yellapragada is acknowledged for his assistance in data collection. Ms. Muni Rajya Lakshmi is acknowledged for her support with data management. Authors thank Prof. Jill Keeffe, Ms. Neha Hassija, and Dr. Shobha Mocherla for their valuable inputs on earlier versions of the manuscript.

Funding This work was supported by Wellcome Trust/DBT India Alliance Fellowship [IA/CPHE/14/1/501506] awarded to SM and Hyderabad Eye Research Foundation (HERF), India.

\section{Compliance with ethical standards}

Conflict of interest The authors declare that they have no conflict of interest.

Publisher's note Springer Nature remains neutral with regard to jurisdictional claims in published maps and institutional affiliations.

\section{References}

1. Fricke TR, Tahhan N, Resnikoff S, Papas E, Burnett A, Ho SM, et al. Global prevalence of presbyopia and vision impairment from uncorrected presbyopia: systematic review, meta-analysis, and modelling. Ophthalmology. 2018;125:1492-9. 
2. Holden BA, Fricke TR, Ho SM, Wong R, Schlenther G, Cronje S, et al. Global vision impairment due to uncorrected presbyopia. Arch Ophthalmol. 2008;126:1731-9.

3. He M, Abdou A, Naidoo KS, Sapkota YD, Thulasiraj RD, Varma $\mathrm{R}$, et al. Prevalence and correction of near vision impairment at seven sites in China, India, Nepal, Niger, South Africa, and the United States. Am J Ophthalmol. 2012;154:107-16 e101.

4. Han X, Lee PY, Keel S, He M. Prevalence and incidence of presbyopia in urban Southern China. Br J Ophthalmol. 2018; 102:1538-42.

5. Hashemi H, Khabazkhoob M, Jafarzadehpur E, Mehravaran S, Emamian MH, Yekta A, et al. Population-based study of presbyopia in Shahroud, Iran. Clin Exp Ophthalmol. 2012;40:863-8.

6. Laviers $H$. The prevalence of presbyopia and the feasibility of community distribution of near spectacles in adults in Zanzibar, East Africa. Community Eye Health. 2007;20:73.

7. Lu Q, He W, Murthy GV, He X, Congdon N, Zhang L, et al. Presbyopia and near-vision impairment in rural northern China. Invest Ophthalmol Vis Sci. 2011;52:2300-5.

8. Marmamula S, Keeffe JE, Rao GN. Uncorrected refractive errors, presbyopia and spectacle coverage: results from a rapid assessment of refractive error survey. Ophthalmic Epidemiol. 2009;16: 269-74.

9. Mashayo ER, Chan VF, Ramson P, Chinanayi F, Naidoo KS. Prevalence of refractive error, presbyopia and spectacle coverage in Kahama District, Tanzania: a rapid assessment of refractive error. Clin Exp Optometry: J Aust Optometrical Assoc. 2015;98:58-64.

10. Nirmalan PK, Krishnaiah S, Shamanna BR, Rao GN, Thomas R. A population-based assessment of presbyopia in the state of Andhra Pradesh, South India: the Andhra Pradesh Eye Disease Study. Invest Ophthalmol Vis Sci. 2006;47:2324-8.

11. Obajolowo TS, Owoeye J, Adepoju FG. Prevalence and pattern of presbyopia in a rural Nigerian community. J West Afr Coll Surg. 2016;6:83-104.

12. Patel I, Munoz B, Burke AG, Kayongoya A, McHiwa W, Schwarzwalder AW, et al. Impact of presbyopia on quality of life in a rural African setting. Ophthalmology. 2006;113:728-34.

13. Patel I, West SK. Presbyopia: prevalence, impact, and interventions. Community Eye Health. 2007;20:40-1.

14. Frick KD, Joy SM, Wilson DA, Naidoo KS, Holden BA. The global burden of potential productivity loss from uncorrected presbyopia. Ophthalmology. 2015;122:1706-10.

15. Reddy PA, Congdon N, MacKenzie G, Gogate P, Wen Q, Jan C, et al. Effect of providing near glasses on productivity among rural Indian tea workers with presbyopia (PROSPER): a randomised trial. Lancet Glob Health. 2018;6:e1019-27.
16. Marmamula S, Barrenkala NR, Challa R, et al. Hyderabad Ocular Morbidity in Elderly Study (HOMES)—rationale, study design and methodology. Ophthalmic Epidemiol. 2020;27:83-92.

17. Marmamula S, Barrenkala NR, Challa R, Kumbam TR, Modepalli $\mathrm{SB}$, Yellapragada $\mathrm{R}$, et al. Uncorrected refractive errors for distance among the residents in 'homes for the aged' in South India - the Hyderabad Ocular Morbidity in Elderly Study (HOMES). Ophthalmic Physiol Opt. 2020;40:343-9.

18. Marmamula S, Barrenakala NR, Challa R, Kumbham TR, Modepalli SB, Yellapragada R, et al. Prevalence and risk factors for visual impairment among elderly residents in 'homes for the aged' in India: the Hyderabad Ocular Morbidity in Elderly Study (HOMES). Br J Ophthalmol. 2020 Mar 25:bjophthalmol-2019315678. https://doi.org/10.1136/bjophthalmol-2019-315678.

19. Lu Q, Congdon N, He X, Murthy GV, Yang A, He W. Quality of life and near vision impairment due to functional presbyopia among rural Chinese adults. Invest Ophthalmol Vis Sci. 2011; 52:4118-23.

20. Patel I, West SK. Functional presbyopia in Kenya. Clin Exp Ophthalmol. 2008;36:699-700.

21. Bourne RR. Uncorrected refractive error and presbyopia: accommodating the unmet need. Br J Ophthalmol. 2007;91: 848-50.

22. Burke AG, Patel I, Munoz B, Kayongoya A, McHiwa W, Schwarzwalder AW, et al. Population-based study of presbyopia in rural Tanzania. Ophthalmology. 2006;113:723-7.

23. Marmamula S, Narsaiah S, Shekhar K, Khanna RC. Presbyopia, spectacles use and spectacle correction coverage for near vision among cloth weaving communities in Prakasam district in South India. Ophthalmic Physiol Opt. 2013;33:597-603.

24. Muhit M, Minto H, Parvin A, Jadoon MZ, Islam J, Yasmin S, et al. Prevalence of refractive error, presbyopia, and unmet need of spectacle coverage in a northern district of Bangladesh: rapid assessment of refractive error study. Ophthalmic Epidemiol. 2018;25:126-32.

25. Marmamula S, Ravuri LV, Boon MY, Khanna RC. Spectacle coverage and spectacles use among elderly population in residential care in the south Indian state of Andhra Pradesh. Biomed Res Int. 2013;2013:183502.

26. Marmamula S, Khanna RC, Narsaiah S, Shekhar K, Rao GN. Prevalence of spectacles use in Andhra Pradesh, India: rapid assessment of visual impairment project. Clin Exp Ophthalmol. 2014;42:227-34.

27. Marmamula S, Khanna RC, Kunuku E, Rao GN. Near visual impairment and spectacle coverage in Telangana, India. Clin Exp Ophthalmol. 2017;45:568-74. 